\title{
Impact of structure and flow-path on in situ synthesis of AIN: Dynamic microstructural evolution of Al-AIN-Si materials
}

\author{
Zhe Wang $^{1 *}$ Xin Wang ${ }^{1}$, Yigang Tong ${ }^{1}$ and Yaping Wang ${ }^{1,2^{*}}$
}

\begin{abstract}
The Al-AlN-Si composites were prepared in the gas-in-liquid in situ synthesized flow-reaction-system, which was implemented by a powder metallurgy and reaction sintering route. The experimental results showed that Al-AlN$50 \mathrm{Si}^{\mathrm{B}}$ material (prepared by ball-milling powders) and AlAlN-50Si ${ }^{\mathrm{M}}$ material (prepared by mixing powders) exhibited the semi-continuous $\mathrm{Si}$ structures and the isolated $\mathrm{Si}$ islands, respectively. Subsequently, the Al-AlN-50Si materials were selected as the model materials by phase identification and microstructure analysis. The dynamic microstructural evolution of Al-AlN-50Si materials was investigated using the computational fluid dynamics (CFD) method. Mathematical models and simulation results showed that the in situ synthesis of AlN was strongly influenced by the structure and the flowpath $\left(\left(c_{\mathrm{g}, \mathrm{N}} / l_{\mathrm{g,N}}\right)+\left(c_{\mathrm{s}, \mathrm{AIN}} / l_{\mathrm{s}, \mathrm{AIN}}\right)\right)$. The flow paths of Al-AIN-50Si ${ }^{\mathrm{B}}$ material were restricted by the semi-continuous $\mathrm{Si}$. These Si structures can promote the formation of the strong turbulence with gradually weakened fluctuation, so that the in situ synthesis of AlN was interconnected and surrounded by an interpenetrating Si network. In contrast, the flow paths of AlAlN-50Si ${ }^{\mathrm{M}}$ material can easily pass through the isolated Si due to its mild turbulence with linear relationship. As a result, AlN was separated by the isolated $\mathrm{Si}$ and agglomerated in the matrix. Overall, the present work provides new insights into dynamic microstructural evolution in in situ reaction sintering systems.
\end{abstract}

Keywords: Al-AlN-Si materials, flow-reaction-system, turbulence, flow path

\section{INTRODUCTION}

Al-AlN-Si materials, one of the Al-Si based composites [1-4], have a wide range of potential application in thermal management materials due to their low thermal expansion coefficient and high thermal conductivity [511]. Al-AlN-Si materials with high $\mathrm{Si}$ content can be prepared in the gas-in-liquid in situ synthesized flowreaction-system. All the processes are implemented by a powder metallurgy and reaction sintering route, which is an efficient, economical and environmentally friendly way to synthesize Al-AlN-Si composites. However, the flow-reaction may be affected by the flow paths of gas and liquid turbulence, due to the in situ reaction of $\mathrm{N}_{2}$ with molten $\mathrm{Al}$ in $\mathrm{Al}-\mathrm{AlN}-\mathrm{Si}$ materials during the nitrogen sintering process. Thus, the evolution process of microstructures can become complex with the advancing multiphase-flow-solidification, especially in the $\mathrm{Al}-\mathrm{Si}$ matrix with high Si content. To better understand the formation mechanism of AlN in Al-AlN-Si materials, the investigation of microstructural dynamic evolutions are required.

In recent years, in order to reveal the microstructural evolution of Al-Si based materials, experimentally, some studies have investigated the effect of the modifier elements (e.g., sodium, strontium and phosphorus) on the microstructural evolution of Al-Si based composites [1215]. The morphology of Al-Si based alloys can be affected by the modifier content, due to the formation of aluminous mesophase [16-17]. Others focused on the impact of the additional or the in situ synthesized phases on microstructure of Al-Si based materials, such as magnesium, silicon carbide, silicon nitride [18-20], etc. However, the dynamic evolution process of microstructure cannot be easily detected by observers, and the understanding of formation mechanism of microstructure is substantially incomplete. The mathematical computation and simula-

${ }^{1}$ MOE Key Laboratory for Nonequilibrium Synthesis and Modulation of Condensed Matter, School of Science, Xi'an Jiaotong University, Xi'an 710049, China

${ }^{2}$ State Key Laboratory for Mechanical Behavior of Materials, Xi'an Jiaotong University, Xi'an 710049, China

* Corresponding authors (emails: ypwang@mail.xjtu.edu.cn (Wang Y); cangture@gmail.com (Wang Z)) 
tion can be reasonably effective in predicting the detailed insight into the dynamic evolution of microstructure [21, 22]. For example, Eiken et al. [23] reported the impact of the addition of $\mathrm{P}$ and $\mathrm{Sr}$ on solidification sequence of Al$\mathrm{Si}$ alloys by means of the thermodynamic computation. Researchers have also elucidated the evolution of the eutectic morphology using the 3D phase-field simulation. However, so far, few studies focus on the dynamic microstructural evolution of in situ synthesized phase in Al$\mathrm{Si}$ based composites, likely due to their complex reactionturbulence interaction. Additionally, the observation of microstructural evolution, especially in the Al-Si based materials with high Si content, is unachievable in experiments. Thus the formation mechanism of microstructure for the in situ synthesized $\mathrm{Al}-\mathrm{Si}$ based composites remains unclear.

In this study, the Al-AlN-50Si materials were fabricated by the high-energy ball milled or the mixed powders following nitrogen atmosphere sintering. Subsequently, the Al-AlN-50Si materials with semi-continuous $\mathrm{Si}$ structures (Al-AlN-50Si ${ }^{\mathrm{B}}$ ) and isolated Si islands (Al-AlN$50 \mathrm{Si}^{\mathrm{M}}$ ) were selected as the model materials by phase identification and microstructure analysis. Aiming at understanding the dynamic evolution of microstructure, we employed the mathematical models and CFD (computational fluid dynamics) with UDF (user defined function) simulations to obtain detailed insight into the in situ synthesis of AlN. With the help of the multiphaseflow-solidification system, the impact of gas and liquid turbulence, microstructure and flow-path on the dynamic microstructural evolution was investigated, and the mechanism of in situ synthesized AlN was elucidated.

\section{METHODS}

\section{Experimental methodology}

The Al powders (99.9\% purity) and Si powders $(99.9 \%$ purity) were commercially available pure powders. The $\mathrm{Si}$ powders with the contents of 50 wt.\% were mixed or high-energy ball milled with $\mathrm{Al}$ powders together. The mixing was carried out in a Simoloyer miller with hardened alloy vial and balls in the absolute ethanol media for $1 \mathrm{~h}$ at room temperature, and the parameters of highenergy ball milling process are listed in Table 1. In the first step, the as milled and mixed powders were dried in vacuum oven at room temperature. The mixture was compacted under the pressure of $100 \mathrm{MPa}$ into $\varphi 35 \times 15 \mathrm{~mm}$ billets, which were then consolidated by the nitrogen atmosphere at $1020^{\circ} \mathrm{C}$ for $4 \mathrm{~h}$, further consolidated by hot-pressing in the graphite die at $600^{\circ} \mathrm{C}$ and
Table 1 High-energy ball milling parameters

\begin{tabular}{cccc}
\hline Ball/powder ratio & $\begin{array}{c}\text { Milling } \\
\text { speed (rmp) }\end{array}$ & $\begin{array}{c}\text { Milling } \\
\text { time (h) }\end{array}$ & Milling media \\
\hline $10: 1$ & 500 & 1 & Ethanol \\
\hline
\end{tabular}

held for $1 \mathrm{~h}$ at $30 \mathrm{MPa}$. In parallel, a mixed sample was also prepared in the same process.

The phase structure of the powders and samples were determined by an XRD-7000S diffractometer (Shimadzu, Ltd., Kyoto, Japan) using Cu Ka radiation $(\lambda=1.54060 \AA)$ operated at $40 \mathrm{kV}$ and $40 \mathrm{~mA}$. The morphology of the powders and the microstructure of the specimens were characterized by a field-emission scanning electron microscope (SEM, JEOL JSM-7000F) equipped with an energy dispersion spectrometer (EDS) and a backscattered electron detector (EBSD).

\section{Numerical model}

The simulation of reaction sintering process for Al-AlN$50 \mathrm{Si}^{\mathrm{B}}$ and $\mathrm{Al}-\mathrm{AlN}-50 \mathrm{Si}^{\mathrm{M}}$ materials was performed using the computational fluid dynamics code, ANSYS-FLUENT software (ANSYS Inc., USA) which uses a finite element numerical method [24,25]. The conservation principles of mass, momentum and energy were calculated considering the continuity equation for the incompressible fluid. At steady state, the meshed strand geometries were generated by the pre-processing tool GAMBIT (ANSYS, Inc., USA). After functional volume meshes had been produced, mesh refinement was continued iteratively until numerical flow solutions converged. Subsequently, all flow simulations were performed by ANSYS-FLUENT, and the flow-reaction of species was solved by using UDF function and SIMPLE algorithm [26]. A 3D scale model of columnar sample $(\varphi 3.5 \times 1.5 \mathrm{~mm})$ of Al-50Si (wt.\%) with $\mathrm{N}_{2}$ reaction was considered. To ensure a relatively high accuracy solution, the time step was determined empirically by test simulations. In this study, all calculations were run with a time step of $0.01 \mathrm{~s}$, and the maximum iteration per time step was set to 100 . The details of the material properties, boundary conditions and model parameters were summarized in Table 2. For the simplicity of the discussion, some parameters were simplified in this case. In addition, the implementation of the experimental and simulated procedures was illustrated in Fig. 1.

The diffusion-reaction-system can be constructed to study the formation mechanism of AlN in $\mathrm{Al}-\mathrm{AlN}-50 \mathrm{Si}^{\mathrm{B}}$ and $\mathrm{Al}-\mathrm{AlN}-50 \mathrm{Si}^{\mathrm{M}}$ materials deeply. At the interface between $\mathrm{Al}$ and $\mathrm{N}_{2}$, we assume that the instantaneous velocity of liquid and gas phases is zero. Additionally, the 
Table 2

\begin{tabular}{|c|c|c|c|c|}
\hline Parameter & $\mathrm{Al}$ & $\mathrm{Si}$ & $\mathrm{N}_{2}$ & AlN \\
\hline Atomic fraction (\%) & 27.0 & 28.1 & 28.0 & 41.0 \\
\hline Melting point (K) & 933 & 1683 & 62 & 2500 \\
\hline Density $\left(\mathrm{kg} \mathrm{m}^{-3}\right)$ & 2698 & 2328 & 313 & 3260 \\
\hline Specific heat $\left(\mathrm{J} \mathrm{kg}^{-1} \mathrm{~K}^{-1}\right)$ & 896 & 710 & 741 & 940 \\
\hline Viscosity $\left(\mathrm{kg} \mathrm{m}^{-1} \mathrm{~s}^{-1}\right)$ & $1.420 \times 10^{-3}$ & - & $0.025 \times 10^{-3}$ & - \\
\hline Heat conductivity ( $\mathrm{W} \mathrm{m}{ }^{-1} \mathrm{~K}^{-1}$ ) & 237 & 148 & $25 \times 10^{-3}$ & 320 \\
\hline Thermal expansion coefficient $\left(\mathrm{K}^{-1}\right)$ & $23.6 \times 10^{-4}$ & $4.1 \times 10^{-6}$ & $3.7 \times 10^{-3}$ & $4.5 \times 10^{-6}$ \\
\hline Initial temperature $(\mathrm{K})$ & \multicolumn{4}{|c|}{993} \\
\hline Maximum temperature (K) & \multicolumn{4}{|c|}{1293} \\
\hline External temperature $(\mathrm{K})$ & \multicolumn{4}{|c|}{300} \\
\hline Grid size $(\mathrm{mm})$ & \multicolumn{4}{|c|}{$1 \times 10^{-3}$} \\
\hline Walls & \multicolumn{4}{|c|}{ Adiabatic, non-slip } \\
\hline
\end{tabular}

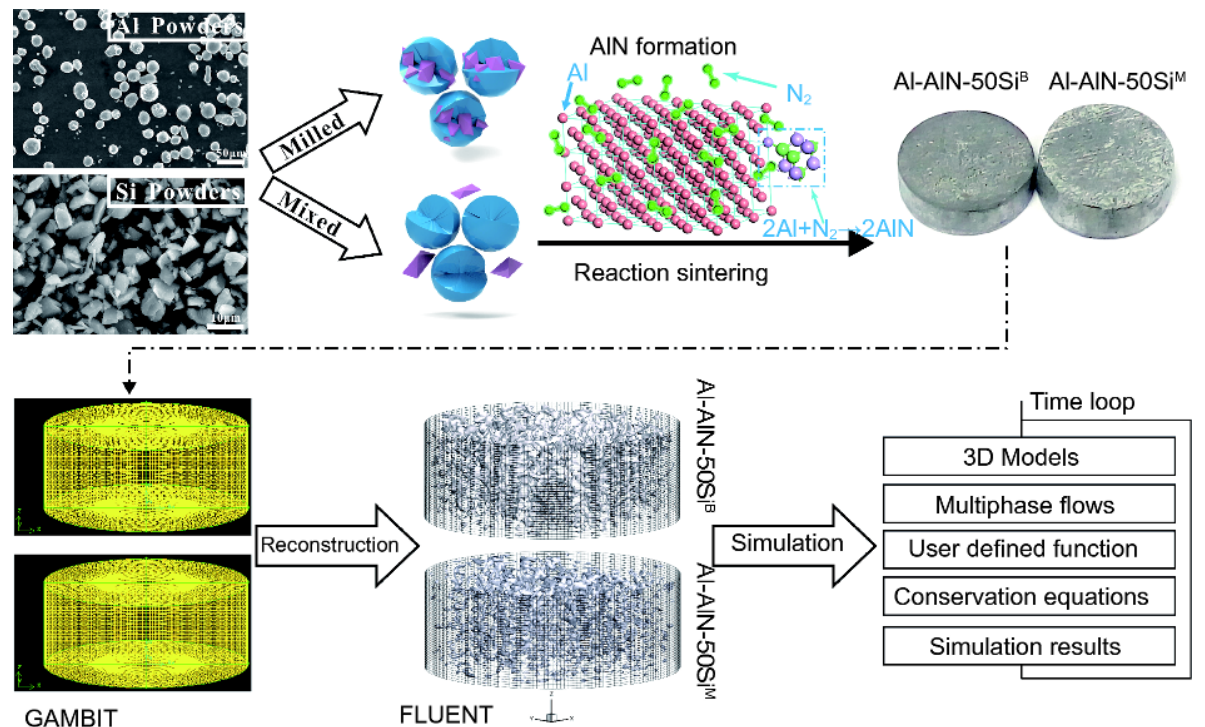

Figure 1 Schematic illustration of the experimental and simulated procedures of materials.

participation of $\mathrm{Al}$ in the reaction can be considered as infinite and the incomplete reaction of $\mathrm{N}_{2}$ is ignored, so that the gaseous $\mathrm{N}_{2}$ can be completely consumed by the liquid $\mathrm{Al}$ to form the solid AlN. To focus on the effect of flow on the in situ synthesis of AlN, the flow caused by density difference of species on the reaction interface can be ignored for the instantaneous reaction of gas to solid, i.e., $\rho_{\mathrm{g}}=\rho_{\mathrm{s}}$ (from reaction interface). While the density difference of species which do not participate in the reaction cannot be ignored. For the simplicity, the species conservation equation in the reaction areas is written as: $\mathrm{d}\left(f_{\mathrm{g}} \rho_{\mathrm{g}} c_{\mathrm{g}}+f_{\mathrm{s}} \rho_{\mathrm{s}} c_{\mathrm{s}}\right) / \mathrm{d} t=0$ ( $f$ is volume fraction; $\rho$ is the density; $c$ is species concentration.), i.e.

$$
\rho_{\mathrm{g}} f_{\mathrm{g}} \frac{\mathrm{d} c_{\mathrm{g}}}{\mathrm{d} t}+\rho_{\mathrm{g}} c_{\mathrm{g}} \frac{\mathrm{d} f_{\mathrm{g}}}{\mathrm{d} t}+\rho_{\mathrm{s}} f_{\mathrm{s}} \frac{\mathrm{d} c_{\mathrm{s}}}{\mathrm{d} t}+\rho_{\mathrm{s}} c_{\mathrm{s}} \frac{\mathrm{d} f_{\mathrm{s}}}{\mathrm{d} t}=0 .
$$

We may write $\left(c^{*}\right.$ is interface concentration.):

$$
\begin{aligned}
& \rho_{\mathrm{g}} f_{\mathrm{g}} \frac{\mathrm{d} c_{\mathrm{g}}}{\mathrm{d} t}+\rho_{\mathrm{g}} c_{\mathrm{g}}^{*} \frac{\mathrm{d} f_{\mathrm{g}}}{\mathrm{d} t}-\rho_{\mathrm{g}}\left(c_{\mathrm{g}}^{*}-c_{\mathrm{g}}\right) \frac{\mathrm{d} f_{\mathrm{g}}}{\mathrm{d} t}+\rho_{\mathrm{s}} f_{\mathrm{s}} \frac{\mathrm{d} c_{\mathrm{s}}}{\mathrm{d} t} \\
& -\rho_{\mathrm{s}} c_{\mathrm{s}}^{*} \frac{\mathrm{d} f_{\mathrm{g}}}{\mathrm{d} t}+\rho_{\mathrm{s}}\left(c_{\mathrm{s}}^{*}-c_{\mathrm{s}}\right) \frac{\mathrm{d} f_{\mathrm{g}}}{\mathrm{d} t}=0 .
\end{aligned}
$$

As ( $S$ is surface concentration and $l$ is flow path length.) 


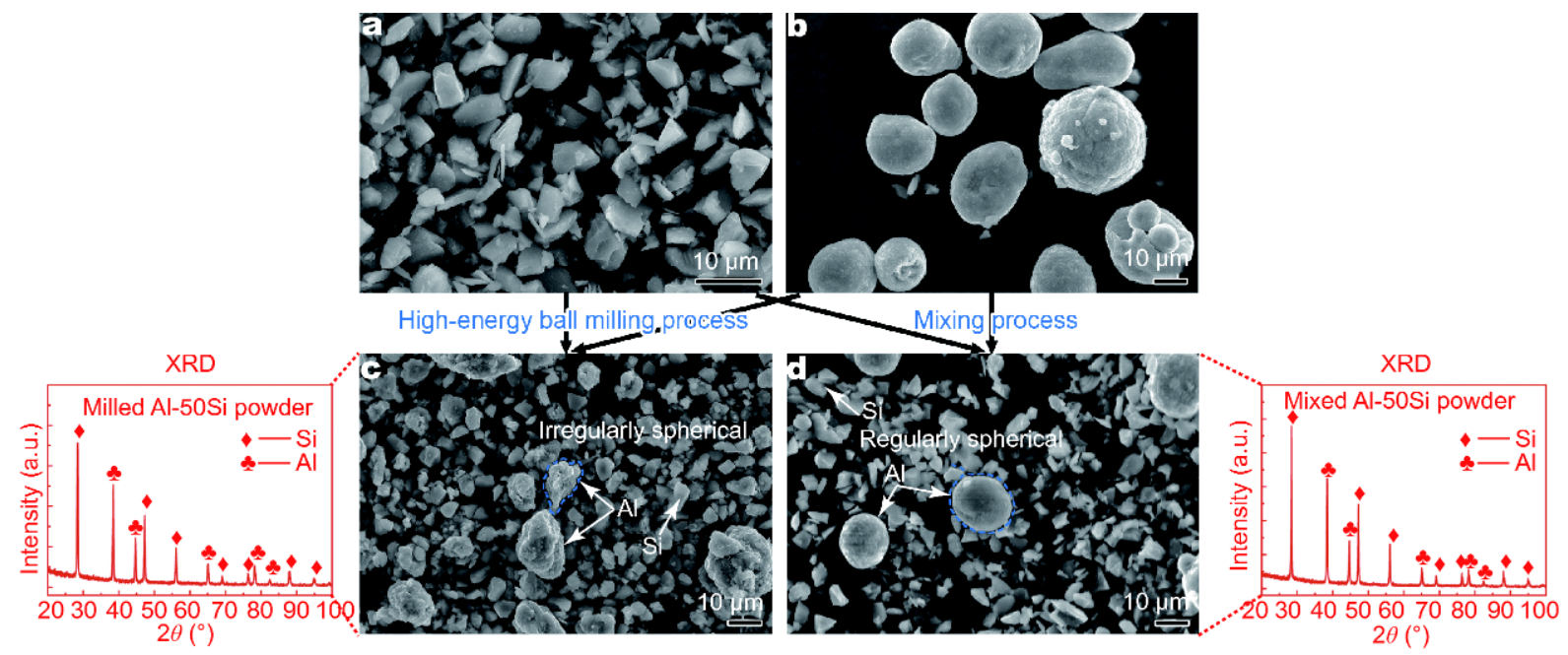

Figure 2 SEM images of the morphology of powders: silicon (a), aluminum (b), high-energy ball milled powders (c) and mixed powders (d). XRD spectra of high-energy ball milled powders (inset of Fig. 2c) and mixed powders (inset of Fig. 2d).

$[22,27]$

$$
\rho_{\mathrm{g}} \cdot S_{\mathrm{sg}} \cdot D_{\mathrm{g}} \frac{\left(c_{\mathrm{g}}^{*}-c_{\mathrm{g}}\right)}{l_{\mathrm{g}}}+\rho_{\mathrm{g}}\left(c_{\mathrm{g}}^{*}-c_{\mathrm{g}}\right) \frac{\mathrm{d} f_{\mathrm{g}}}{\mathrm{d} t}=\rho_{\mathrm{g}} f_{\mathrm{g}} \frac{\mathrm{d} c_{\mathrm{g}}}{\mathrm{d} t}
$$

and

$$
\rho_{\mathrm{s}}\left(c_{\mathrm{s}}^{*}-c_{\mathrm{s}}\right) \frac{\mathrm{d} f_{\mathrm{g}}}{\mathrm{d} t}+\rho_{\mathrm{s}} f_{\mathrm{s}} \frac{\mathrm{d} c_{\mathrm{s}}}{\mathrm{d} t}=\rho_{\mathrm{s}} \cdot S_{\mathrm{sg}} \cdot D_{\mathrm{s}} \frac{\left(c_{\mathrm{s}}^{*}-c_{\mathrm{s}}\right)}{l_{\mathrm{s}}},
$$

using Equation 3 and 4 to substitute Equation 2, we obtain

$$
\begin{aligned}
\rho_{\mathrm{g}} & S_{\mathrm{sg}} \cdot D_{\mathrm{g}} \frac{\left(c_{\mathrm{g}}^{*}-c_{\mathrm{g}}\right)}{l_{\mathrm{g}}}+\rho_{\mathrm{s}} \cdot S_{\mathrm{sg}} \cdot D_{\mathrm{s}} \frac{\left(c_{\mathrm{s}}^{*}-c_{\mathrm{s}}\right)}{l_{\mathrm{s}}} \\
& =\rho_{\mathrm{s}}\left(c_{\mathrm{s}}^{*}-c_{\mathrm{g}}^{*}\right) \frac{\mathrm{d} f_{\mathrm{g}}}{\mathrm{d} t} .
\end{aligned}
$$

Replacing $v_{R_{\mathrm{g}}} \cdot S_{\mathrm{sg}}=\frac{\mathrm{d} f_{\mathrm{g}}}{\mathrm{d} t}$ and $M_{\mathrm{sg}}=v_{R_{\mathrm{g}}} \cdot \rho_{\mathrm{g}} \cdot S_{\mathrm{sg}}$ in Equation 5 ( $M$ is mass transfer rate.) [27], we have

$$
\frac{D_{\mathrm{s}}}{l_{\mathrm{s}}} \cdot \frac{\left(c_{\mathrm{s}}^{*}-c_{\mathrm{s}}\right)}{\left(c_{\mathrm{s}}^{*}-c_{\mathrm{g}}^{*}\right)}+\frac{D_{\mathrm{g}}}{l_{\mathrm{g}}} \cdot \frac{\left(c_{\mathrm{g}}^{*}-c_{\mathrm{g}}\right)}{\left(c_{\mathrm{s}}^{*}-c_{\mathrm{g}}^{*}\right)}=\frac{M_{\mathrm{sg}}}{\rho_{\mathrm{g}} \cdot S_{\mathrm{sg}}},
$$

where we define $c_{1}=\frac{\left(c_{\mathrm{s}}^{*}-c_{\mathrm{s}}\right)}{\left(c_{\mathrm{s}}^{*}-c_{\mathrm{g}}^{*}\right)}$ and $c_{2}=\frac{\left(c_{\mathrm{g}}^{*}-c_{\mathrm{g}}\right)}{\left(c_{\mathrm{s}}^{*}-c_{\mathrm{g}}^{*}\right)}$, then substituting them into Equation 6 yields

$$
\frac{M_{\mathrm{sg}}}{\rho_{\mathrm{g}} \cdot S_{\mathrm{sg}}}=\frac{D_{\mathrm{s}} \cdot c_{1}}{l_{\mathrm{s}}}+\frac{D_{\mathrm{g}} \cdot c_{2}}{l_{\mathrm{g}}}
$$

In the left hand side of Equation 7 , the term is the enrichment from gas to solid (i.e., in situ synthesis of AlN), which governs the microstructural dynamic evolution of materials. The dynamic microstructural evolution is the result of two contributions, corresponding to the two right hand (RHS) side terms of Equation 7. The denominators of RHS is the diffused concentration distribution of species (i.e., structural formation), and the numerator of RHS is the flow lengths of species (i.e., flowpath). The flow paths of solid phase are the interaction between liquid and gas flow paths. Hence, the in situ synthesis of AlN is strongly influenced by two factors: (1) structure, (2) flow-path.

\section{RESULTS}

\section{Powder characterization}

The morphology of feedstock and precursor powders is shown in Fig. 2. Fig. $2 \mathrm{a}$ and $\mathrm{b}$ present the micrographs of $\mathrm{Si}$ and $\mathrm{Al}$ powders, respectively. Noticeably, the Si powders show an angular flake like shape with a mean particle size of $5 \mu \mathrm{m}$, and the $\mathrm{Al}$ powders show a regular spherical shape with an average size of approximately $20 \mu \mathrm{m}$. The micrographs of Al-50Si (wt.\%) powders after high-energy ball milling and mixing are shown in Fig. $2 \mathrm{c}$ and d, and the XRD patterns of $\mathrm{Al}-50 \mathrm{Si}^{\mathrm{B}}$ and $\mathrm{Al}-50 \mathrm{Si}^{\mathrm{M}}$ powers are presented in inset of Fig. $2 \mathrm{c}$ and d, respectively. It is shown that the $\mathrm{Al}$ in the mixed $\mathrm{Al}-50 \mathrm{Si}$ powders have a regular spherical shape with an average size of approximately $20 \mu \mathrm{m}$, which is same as that of initial Al powders. The $\mathrm{Al}$ in the milled Al-50Si powders with the average size of $14 \mu \mathrm{m}$ is noticeably different from that of the mixed Al-50Si powders. It has an irregular cracked shape which is refined by the shear force of the Si particles and cracked into some small $\mathrm{Al}$ particles in the high-energy ball milling process. In addition, the peak of $\mathrm{Al}_{2} \mathrm{O}_{3}$ was hardly seen in XRD pattern of the milled and mixed Al- 

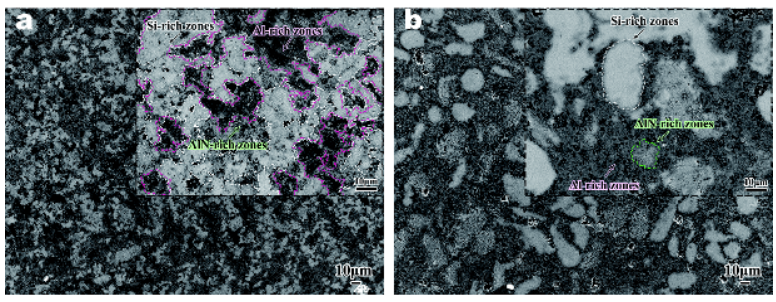

Figure 3 SEM images showing typical microstructures of Al-AlN-50Si ${ }^{\mathrm{B}}$ material (a) and Al-AlN-50Si ${ }^{\mathrm{M}}$ material (b).

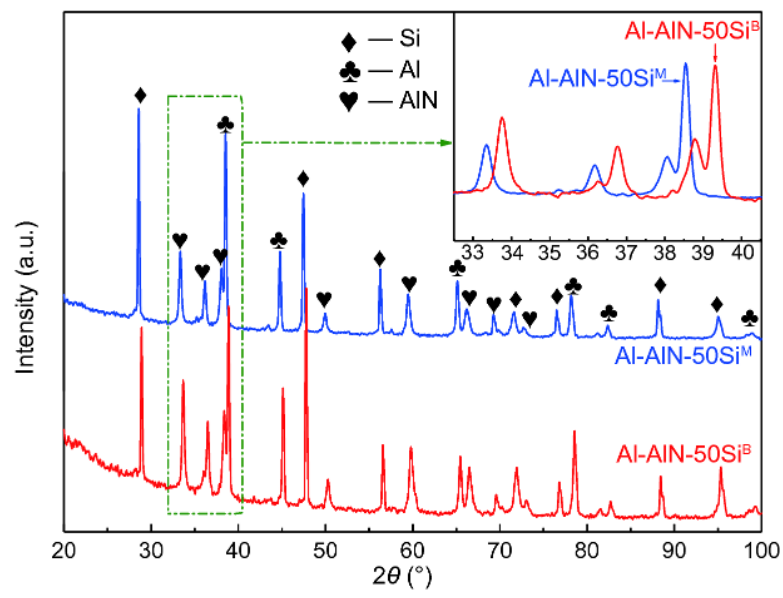

Figure $4 \mathrm{XRD}$ spectra of $\mathrm{Al}-\mathrm{AlN}-50 \mathrm{Si}^{\mathrm{B}}$ and $\mathrm{Al}-\mathrm{AlN}-50 \mathrm{Si}^{\mathrm{M}}$ samples.

50Si powders, revealing that a few oxide films can be striped on the high-energy ball milled powders in ethanol and the formation of new-born oxide film decreases. The high-energy ball milled Al-Si powders have many defects and high surface energy, and the mixtures can easily react with enough $\mathrm{N}_{2}$ to form AlN. Hence, the oxide films cannot widely exist in $\mathrm{Al}$ surface, and the effect of extremely thin oxide films on in situ synthesis of AlN can be ignored.

\section{Microstructure and phase analysis}

Fig. $3 \mathrm{a}$ and $\mathrm{b}$ show the SEM images of Al-AlN-50Si ${ }^{\mathrm{B}}$ and Al-AlN-50Si ${ }^{\mathrm{M}}$ materials, respectively. The XRD patterns of the samples are presented in Fig. 4. It is observed that the main phases are aluminum, silicon and aluminum nitride, and no additional intermetallic or compound can be detected, indicating that AlN can be synthesized by flowing nitrogen gas which reacts with Al-Si materials aided by Si particles. The magnified image of XRD spectra in the green box of Fig. 4 suggests that the main peaks of $\mathrm{Al}, \mathrm{Si}$ and AlN of the Al-AlN-50Si ${ }^{\mathrm{B}}$ materials move to right compared with that of $\mathrm{Al}-\mathrm{AlN}-50 \mathrm{Si}^{\mathrm{M}}$ materials, due

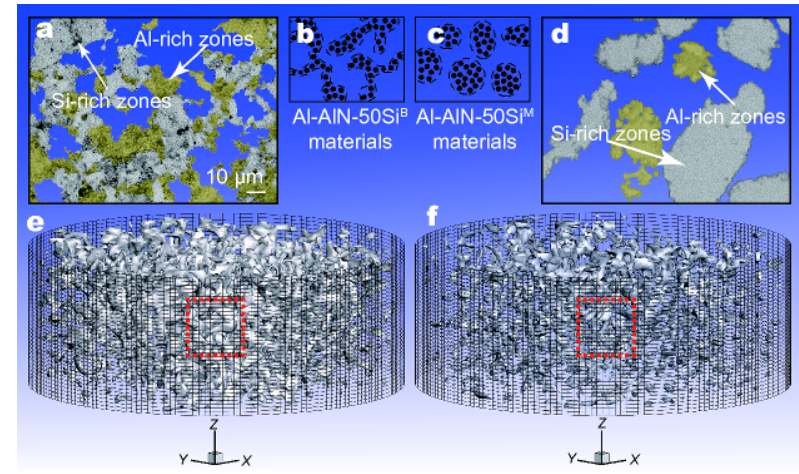

Figure $53 \mathrm{D}$ model and simulation results of materials. The magnified SEM images of model materials, Al-AlN-50Si material (a) and Al-AlN$50 \mathrm{Si}^{\mathrm{M}}$ material (d). Schematic illustrations of microstructures Al-AlN$50 \mathrm{Si}^{\mathrm{B}}$ material (b) and $\mathrm{Al}-\mathrm{AlN}-50 \mathrm{Si}^{\mathrm{M}}$ material (c). Simulation results of $3 \mathrm{D}$ model of Al-AlN-50Si ${ }^{\mathrm{B}}$ material (e) and $\mathrm{Al}-\mathrm{AlN}-50 \mathrm{Si}^{\mathrm{M}}$ material (f).

to the increased strain in crystals. Additionally, the inset images of Fig. 3a and $b$ show the microstructures of materials, and the summary composition of these materials are analyzed by EDS. The results indicate that the dark gray background is Al-rich zone while the light gray zones are $\mathrm{Si} / \mathrm{AlN} / \mathrm{Si}$-AlN rich zones. The AlN-rich zones of Al-AlN-50Si ${ }^{\mathrm{B}}$ materials are surrounded by some semicontinuous structures of Si-rich zones (inside white dotted curves) in interpenetrating Al-rich zones (inside magenta dotted curves). While the $\mathrm{Al}-\mathrm{AlN}-50 \mathrm{Si}^{\mathrm{M}}$ materials show the isolated islands of Si-rich (inside white dotted curves), AlN-rich (inside green dotted curves) and the Si-rich zones are separated from each and agglomerated in $\mathrm{Al}$ matrix.

\section{D model and simulation results}

The numerical simulations were based on this work's experimental results. The numerical simulations only emphasize the mechanism of in situ synthesized AlN during the flow-solidification process, but do not consider the diffusion reaction of solid phases, i.e., the simulation process from 300 to $933 \mathrm{~K}$ is ignored. Based on the phase identification and microstructure analysis of Al-AlN-50Si ${ }^{\mathrm{B}}$ and Al-AlN-50Si ${ }^{\mathrm{M}}$ materials, the Al-AlN50Si materials with semi-continuous structure of $\mathrm{Si}(\mathrm{Al}-$ $\left.\mathrm{AlN}-50 \mathrm{Si}^{\mathrm{B}}\right)$ and isolated islands of $\mathrm{Si}\left(\mathrm{Al}-\mathrm{AlN}-50 \mathrm{Si}^{\mathrm{M}}\right)$ are selected as the model materials. The magnified SEM images of Si-rich zones (gray translucent marked-regions), AlN-rich zones (yellow translucent marked-regions) and Al-rich zones (transparent marked-regions) in $\mathrm{Al}-\mathrm{AlN}-50 \mathrm{Si}^{\mathrm{B}}$ and $\mathrm{Al}-\mathrm{AlN}-50 \mathrm{Si}^{\mathrm{M}}$ materials are shown in Fig. $5 \mathrm{a}$ and $\mathrm{d}$. In the $\mathrm{Al}-\mathrm{AlN}-50 \mathrm{Si}^{\mathrm{B}}$ material, the tiny ceramic phases are agglomerated in some areas and 
formed ceramic-metal interpenetrating networks (Fig. 5b). However, in the Al-AlN-50Si ${ }^{\mathrm{M}}$ material, the cluster regions of ceramic phases are separated and agglomerated in the form of isolated structures (Fig. 5c) [28].

Further, the basis of the experimental microstructures of Al-AlN-50Si ${ }^{\mathrm{B}}$ and $\mathrm{Al}-\mathrm{AlN}-50 \mathrm{Si}^{\mathrm{M}}$ materials, the 3D scale models of columnar samples $(\varphi 3.5 \times 1.5 \mathrm{~mm})$ are constructed. We employ the CFD with UDF simulations to obtain the detailed synthesis of materials and a dynamic evolution of their microstructures by means of the multiphase-flow-solidification model. The initial models include three phases: solid $\mathrm{Si}$ phase, liquid $\mathrm{Al}$ phase and gaseous $\mathrm{N}_{2}$ phase. We define the initial $\mathrm{N}_{2}$ and molten $\mathrm{Al}$ as fluid, which are distributed uniformly in the semicontinuous structure of $\mathrm{Si}$ solid matrix (Al-AlN-50Si $\mathrm{S}^{\mathrm{B}}$ ) and the isolated islands of Si solid matrix $\left(\mathrm{Al}-\mathrm{AlN}-50 \mathrm{Si}^{\mathrm{M}}\right)$, due to the fact that the initial temperature condition can be assumed as $933 \mathrm{~K}$ (the melting point of $\mathrm{Al}$ ) and then the temperature increases from 933 to $1293 \mathrm{~K}$, and then cools down to $300 \mathrm{~K}$. In this process, $\mathrm{N}_{2}$ reacts with $\mathrm{Al}$ to form AlN when the temperature exceeds $933 \mathrm{~K}$. To study the formation of AlN, we focus on the reaction with temperature from heating $933 \mathrm{~K}$ to cooling $933 \mathrm{~K}$, due to the fact that the final AlN are formed mainly at temperature from 1293 to $933 \mathrm{~K}$ and few $\mathrm{N}_{2}$ as reactant remained in the matrix at temperature from 933 to $300 \mathrm{~K}$ $[29,30]$. The transient simulation results of $\mathrm{Al}-\mathrm{AlN}-50 \mathrm{Si}^{\mathrm{B}}$ (Fig. 5e) and $\mathrm{Al}-\mathrm{AlN}-50 \mathrm{Si}^{\mathrm{M}}$ (Fig. 5f) at cooling stage (e.g., $1093 \mathrm{~K}$ ) show the light-gray, yellow and transparent regions are Si-rich, AlN-rich and Al-rich phases.

\section{DISCUSSION}

\section{Dynamic microstructural evolution of materials}

Based on the 3D model of materials, the microstructural dynamic evolution of Al-AlN-50Si materials is investigated in detail. The magnified $3 \mathrm{D}$ images (red box in Fig. 5e, f) of the transient simulation results of $\mathrm{Al}-\mathrm{AlN}$ $50 \mathrm{Si}^{\mathrm{B}}$ and $\mathrm{Al}-\mathrm{AlN}-50 \mathrm{Si}^{\mathrm{M}}$ materials are shown in Fig. 6. In Fig. $6 \mathrm{a}$ and $\mathrm{b}$, the 3D images of $\mathrm{Si}$ phases (light gray regions), AlN phases (yellow regions), $\mathrm{Al}$ phases (transparent regions) and flow streamlines (blue and red arrows) in $\mathrm{Al}-\mathrm{AlN}-50 \mathrm{Si}^{\mathrm{B}}$ and $\mathrm{Al}-\mathrm{AlN}-50 \mathrm{Si}^{\mathrm{M}}$ materials are shown, respectively. As seen in Fig. $6 \mathrm{a}$, the flowing $\mathrm{N}_{2}$ and Al can form many flow channels (streamlines) in the matrix and the AlN is formed around the semi-continuous $\mathrm{Si}$ in the flow paths. Generally, the formation of complex flow channels can be determined by density difference and thermal convection between the liquid and gas phases [31-34]. However, in the Al-AlN-50Si ${ }^{\mathrm{B}}$ mate-

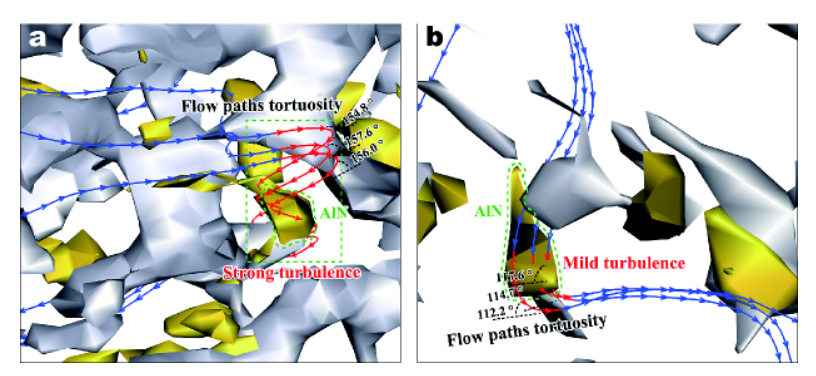

Figure 6 Three-dimensional characterizations of Al-AlN-50 $\mathrm{Si}^{\mathrm{B}}$ material (a) and $\mathrm{Al}-\mathrm{AlN}-50 \mathrm{Si}^{\mathrm{M}}$ material (b). The deflection angles and streamlines of the flow paths are also shown.

rial, the semi-continuous structure of $\mathrm{Si}$ can lead to a more anisotropic structure which strongly influences the flow paths of $\mathrm{N}_{2}$ and Al. These anisotropic structures can form many flowing resistances for $\mathrm{N}_{2}$ and $\mathrm{Al}$, which cause the increase of the flow paths tortuosity. To understand the flowing behavior of $\mathrm{N}_{2}$ and $\mathrm{Al}$, we define the red streamline as large angle flow deflection of flow path. It is observed that the large tortuosity of flow paths is likely to occur around the semi-continuous $\mathrm{Si}$ phases (the red streamlines of Fig. 6a). The deflection angles of this region are about $154.8^{\circ}, 157.6^{\circ}$ and $156.0^{\circ}$, respectively. It is indicated that the large deflection angle of flow paths can increase the flow paths tortuosity and the turbulence intensity (inside the green dotted box), so that the length of flow paths is extended by the semi-continuous Si. Thus, the reaction-time of $\mathrm{N}_{2}$ with $\mathrm{Al}$ is increased and further leads to the probability of AlN formation increased in these regions with large deflection angles.

Unlike the Al-AlN-50Si ${ }^{\mathrm{B}}$ material with semi-continuous $\mathrm{Si}$, the Al-AlN-50Si ${ }^{\mathrm{M}}$ material has a relatively isolated $\mathrm{Si}$ structure which has little effect on the flow deflection of $\mathrm{N}_{2}$ and Al. As seen in Fig. 6b, the isolated island of $\mathrm{Si}$ in $\mathrm{Al}-\mathrm{AlN}-50 \mathrm{Si}^{\mathrm{M}}$ material has a smaller flow deflection angle than that of $\mathrm{Al}-\mathrm{AlN}-50 \mathrm{Si}^{\mathrm{B}}$ material, the deflection angles are about $112.2^{\circ}, 114.7^{\circ}$ and $117.6^{\circ}$, respectively. Compared with the semi-continuous $\mathrm{Si}$ of $\mathrm{Al}-\mathrm{AlN}-50 \mathrm{Si}^{\mathrm{B}}$ material, the isolated $\mathrm{Si}$ of $\mathrm{Al}-\mathrm{AlN}-50 \mathrm{Si}^{\mathrm{M}}$ material is not easy to create a large number of strong turbulent flows in the matrix, and the flow paths with small deflection angle can get around the isolated Si. Thus, AlN is isolated in $\mathrm{Al}$ matrix and not easily formed around the Si.

The deflection angles distribution of flow paths in AlAlN-50Si ${ }^{\mathrm{B}}$ and Al-AlN-50Si ${ }^{\mathrm{M}}$ materials (Fig. 7) reveals that the number of deflection angles of $\mathrm{Al}-\mathrm{AlN}-50 \mathrm{Si}^{\mathrm{B}}$ material in the $>120^{\circ}$ region is greater than that of $\mathrm{Al}-$ AlN-50Si ${ }^{\mathrm{M}}$ material. The number of deflection angles for $\mathrm{Al}-\mathrm{AlN}-50 \mathrm{Si}^{\mathrm{B}}$ material at about $120^{\circ}$ is much higher than 


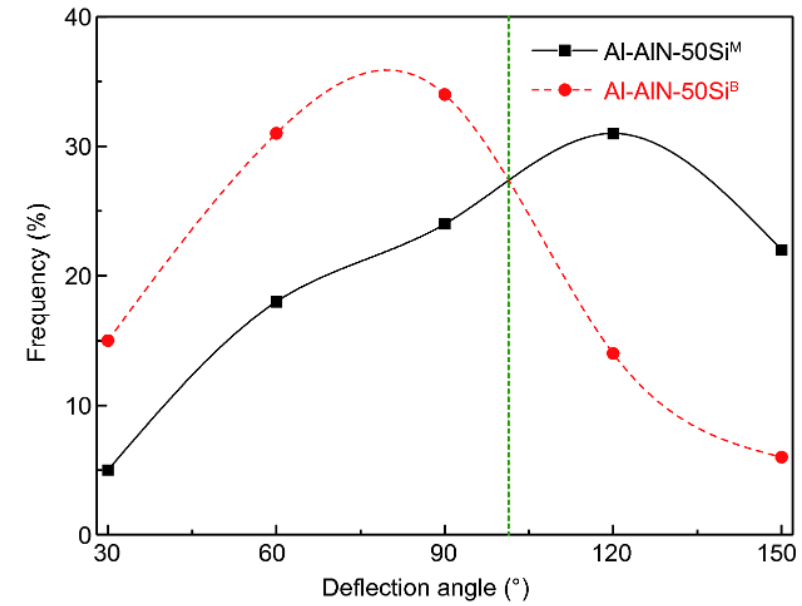

Figure 7 The deflection angles distribution of flow paths in Al-AlN$50 \mathrm{Si}^{\mathrm{B}}$ and $\mathrm{Al}-\mathrm{AlN}-50 \mathrm{Si}^{\mathrm{M}}$ materials.

that of $\mathrm{Al}-\mathrm{AlN}-50 \mathrm{Si}^{\mathrm{M}}$ material in the zones with stronger turbulence intensity. Moreover, the number of deflection angles for Al-AlN-50Si ${ }^{\mathrm{M}}$ material is significantly decreased with increasing deflection angles in the $>120^{\circ}$ region, due to the relatively mild turbulence. Therefore, the flow path is strongly influenced by the deflection angle.

\section{The impact of structure on the in situ synthesis of AlN}

According to Equation 7, the in situ synthesis of AlN is governed by the interaction between the structure $(D \cdot c)$ and the flow-path $(l)$. To further discuss the effect of turbulence on in situ synthesis of AlN in Al-Si materials, the flow streamlines and the species concentration of Al$\mathrm{AlN}-50 \mathrm{Si}^{\mathrm{B}}$ and Al-AlN-50Si ${ }^{\mathrm{M}}$ materials can be calculated using Equation 7. The dynamic evolution of the in situ synthesis of AlN in the profiles of the 3D models of Al$\mathrm{AlN}-50 \mathrm{Si}^{\mathrm{B}}$ material at 10,20 and $80 \mathrm{~s}$ and $\mathrm{Al}-\mathrm{AlN}-50 \mathrm{Si}^{\mathrm{M}}$ material at 10, 15 and $30 \mathrm{~s}$ is shown in Fig. 8 and 9, respectively. During the reaction process, the semi-continuous structure of Si can form many flow channels with multiple directional scales, exhibiting good flow resistance in the presence of multiple directional channels. The isolated island of Si exhibits a relatively free flow path in their flow channels.

In the early stage of the sintering reaction of Al-AlN$50 \mathrm{Si}^{\mathrm{B}}$ material, when the temperature exceeds $933 \mathrm{~K}$, the flowing $\mathrm{N}_{2}$ could in situ react with $\mathrm{Al}$ to form AlN in some channels and then to form the flow paths. Moreover, these complex multiphase flows through the $\mathrm{Si}$ matrix (color scale) can influence the formation of AlN (magenta isolines), which can be synthesized in the flow paths of $\mathrm{N}_{2}$ (pink area) and $\mathrm{Al}$, as shown in the color map $(X=[-0.0300 \mathrm{~mm}, \quad-0.0220 \mathrm{~mm}], \quad Z=[0.0120 \mathrm{~mm}$, $0.0200 \mathrm{~mm}])$ of Fig. 8a. The fraction solid is shown in Fig. $8 \mathrm{~d}$ (the black dash line in the color map). Combined with Fig. 8a, the formation of AlN in the semi-continuous $\mathrm{Si}$ leads to high flowing resistance to control the flow paths. As sintering time increases, the flow paths are further restricted by the flow channels and the semi-continuous structures can lead to the increase of the flow path tortuosity as well as the direction change of AlN flow (Fig.
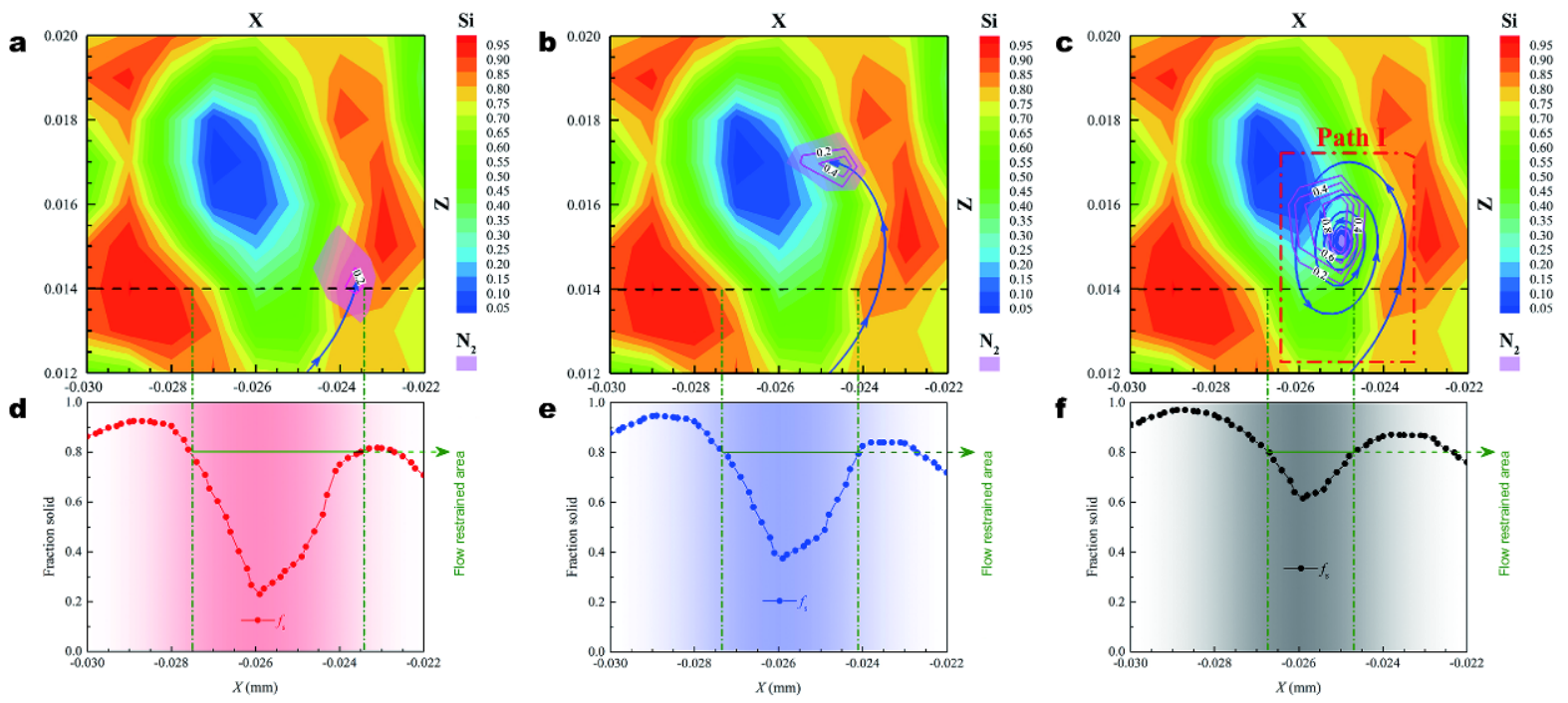

Figure 8 The dynamic evolution of the in situ synthesis of AlN in the profiles of the 3D model of Al-AlN-50Si ${ }^{\mathrm{B}}$ material at $10 \mathrm{~s}(\mathrm{a}), 20 \mathrm{~s}(\mathrm{~b})$ and $80 \mathrm{~s}$ (c). The fraction solid of the black dash line in the color map of Al-AlN-50Si ${ }^{\mathrm{B}}$ material at $10 \mathrm{~s} \mathrm{(d),} 20 \mathrm{~s} \mathrm{(e)}$ and $80 \mathrm{~s}(\mathrm{f})$. 

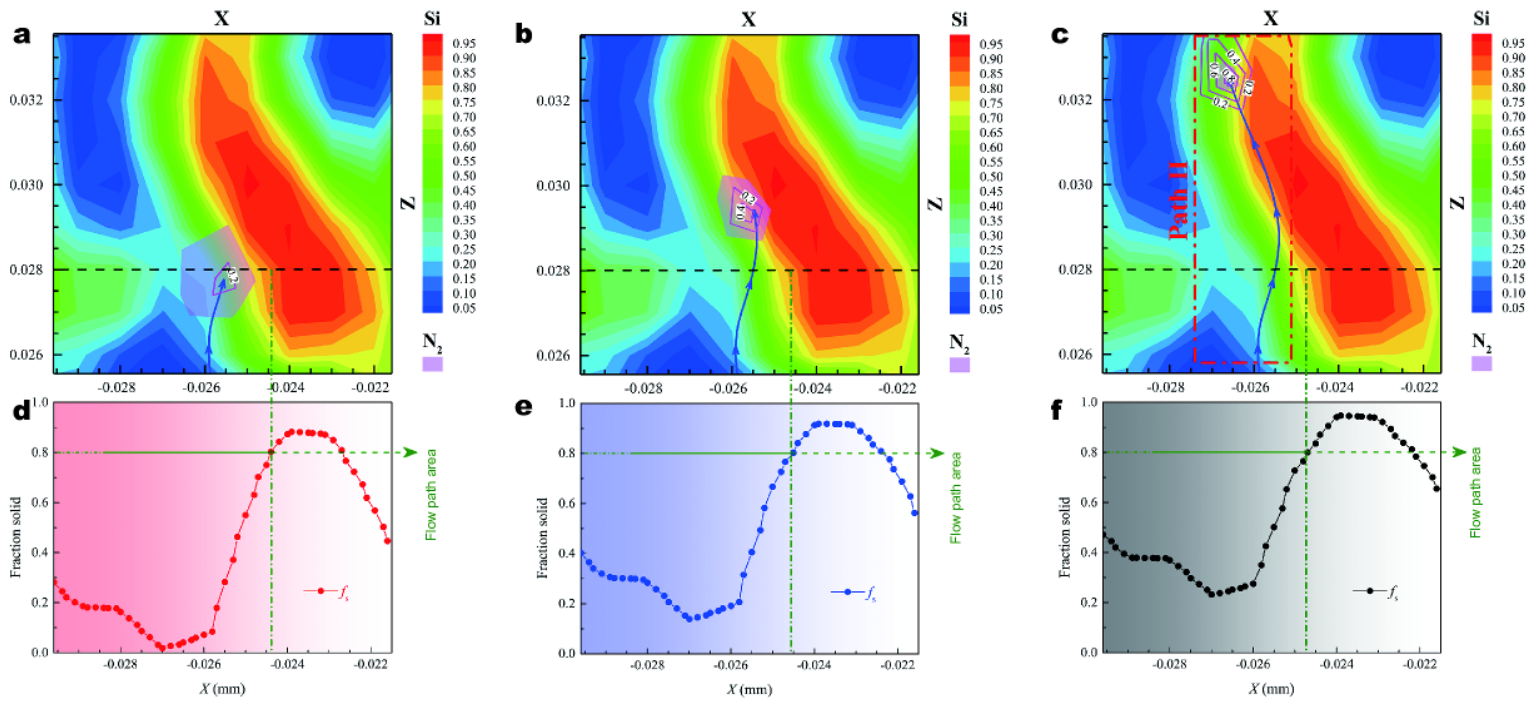

Figure 9 The dynamic evolution of the in situ synthesis of AlN in the profiles of the 3D model of Al-AlN-50Si ${ }^{\mathrm{M}}$ material at $10 \mathrm{~s}(\mathrm{a}), 15 \mathrm{~s}(\mathrm{~b})$ and $30 \mathrm{~s}$ (c). The fraction solid of the black dash line in the color map of Al-AlN-50Si ${ }^{\mathrm{M}}$ material at $10 \mathrm{~s}(\mathrm{~d}), 15 \mathrm{~s}(\mathrm{e})$ and $30 \mathrm{~s}(\mathrm{f})$.

$8 b)$. Thus, the AlN concentration is continuously increased in their flow paths, while the flow areas are reduced (Fig. 8e), especially in the later stage of reaction sintering when the strongly turbulence is formed via the flow channels and the flow paths are completely restricted by the semi-continuous Si (Fig. 8c). As a result, AlN is synthesized around the semi-continuous $\mathrm{Si}$ gradually formed at the end of the flow paths by the advancing solidification interface (Fig. 8f).

The sintering processes of $\mathrm{Al}-\mathrm{AlN}-50 \mathrm{Si}^{\mathrm{M}}$ material are shown in Fig. $9 \mathrm{a}-\mathrm{f}$. The early stage of sintering is shown in the color map $(X=[-0.0296 \mathrm{~mm},-0.0216 \mathrm{~mm}], Z=$ [0.0256 mm, $0.0336 \mathrm{~mm}])$ of Fig. 9a. Obviously, the isolated island of $\mathrm{Si}$ is not easy to change the flow direction at a large deflection angle. The flow paths are hardly constrained by this structure, and the AlN can relatively stable in the flow channel without large deflection of angle. The fraction solid at the black dash line in the color map (Fig. 9a, d) reveals that AlN is formed in the left flow path due to the isolated $\mathrm{Si}$ islands which would not be able to effectively restrain the flow path. In this process, the flow direction of AlN remain nearly unchanged (Fig. $9 \mathrm{~b}$ ), and the flow-reaction of $\mathrm{N}_{2}$ with $\mathrm{Al}$ are almost unaffected by the isolated Si. The AlN concentration increases by the reaction of $\mathrm{N}_{2}$ with $\mathrm{Al}$, and there is no obvious strong turbulence observed in the flow path, as shown in Fig. $9 \mathrm{c}$ and f. Finally, AlN is synthesized mainly only by the advancing solidification interface.

Fig. 10a and b show the Si concentration and the AlN passing position (the black dash line) in the color map
(Figs 8, 9). In Fig. 10a, the semi-continuous Si structure of Al-AlN-50Si ${ }^{\mathrm{B}}$ material can create the flow-restrained areas with low $\mathrm{Si}$ concentration, and the special $\mathrm{Si}$ structure can cause a valley of $\mathrm{Si}$ concentration. In this restrained area, the gas and liquid turbulence leads to the formation of the special flow channels where the AlN is formed by the flow-reaction of $\mathrm{N}_{2}$ and Al. The formed AlN is restricted in the Si-rich zones, thus can pass through the black dash line many times by turbulence as shown in the red curve of Fig. 10a. Additionally, AlN is mainly located in the valley of Si concentration curve and finally is enriched around the Si network and forms an interpenetrating structure (the light grey zone of Fig. 10a). For the Al-AlN-50Si ${ }^{\mathrm{M}}$ material with isolated islands of $\mathrm{Si}$, it is not easy to create the flow restrained areas. The isolated islands of Si cause many free flow channels and the flow-reaction of $\mathrm{N}_{2}$ with $\mathrm{Al}$ is hardly constrained by this structure. Therefore, the free AlN passes through the black dash line just once in this case (the red curve of Fig. $9 b)$. In addition, the isolated structure could not form a valley of $\mathrm{Si}$ concentration curve. Finally, the AlN is formed in the flow free areas and separated by the isolated $\mathrm{Si}$ in the matrix, as seen in the light grey zone of Fig. $10 \mathrm{~b}$.

\section{The impact of flow-path on the in situ synthesis of AlN}

To better understand the effect of flow path on the in situ synthesis of AlN, the detail of the flow-path of Path I in Fig. $8 \mathrm{c}$ and Path II in Fig. $9 \mathrm{c}$ is analysed. Fig. 11a shows dependence of $z$ on time from Path I (red box) of Fig. 8c. 

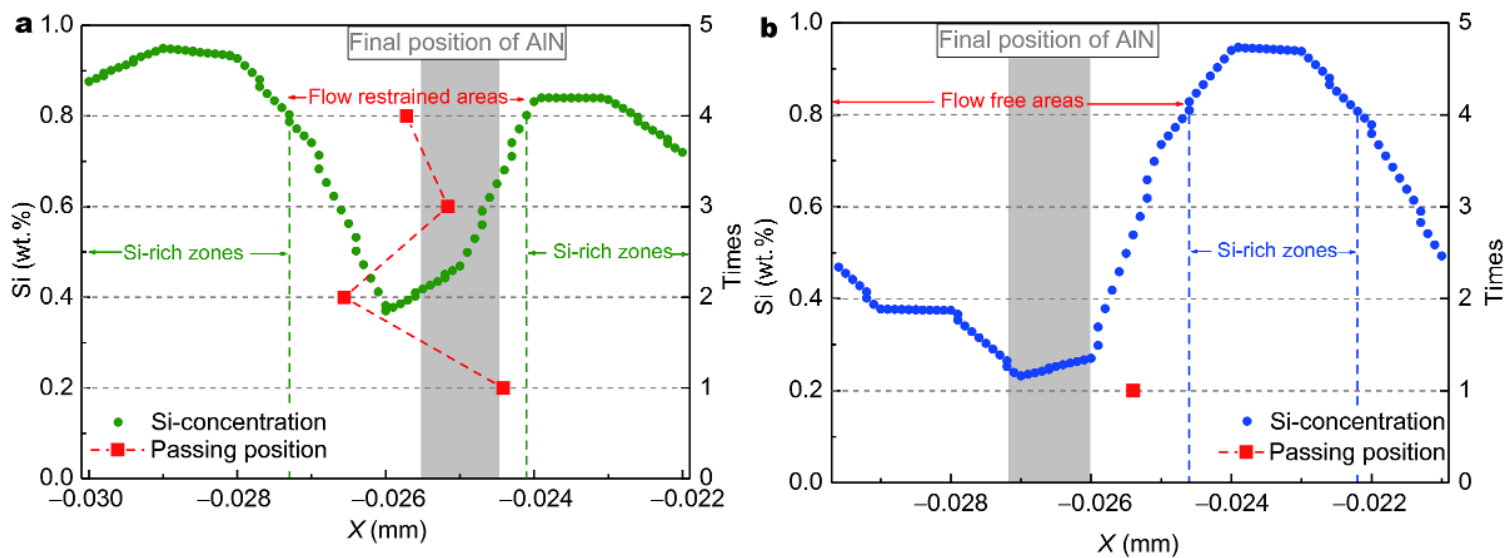

Figure 10 The Si concentration and the AlN passing position of the black dash line in the color map (Figs 8, 9) for $\mathrm{Al}-\mathrm{AlN}^{-50 \mathrm{Si}}{ }^{\mathrm{B}}$ material $(\mathrm{a})$ and $\mathrm{Al}-$ AlN-50Si ${ }^{\mathrm{M}}$ material (b).

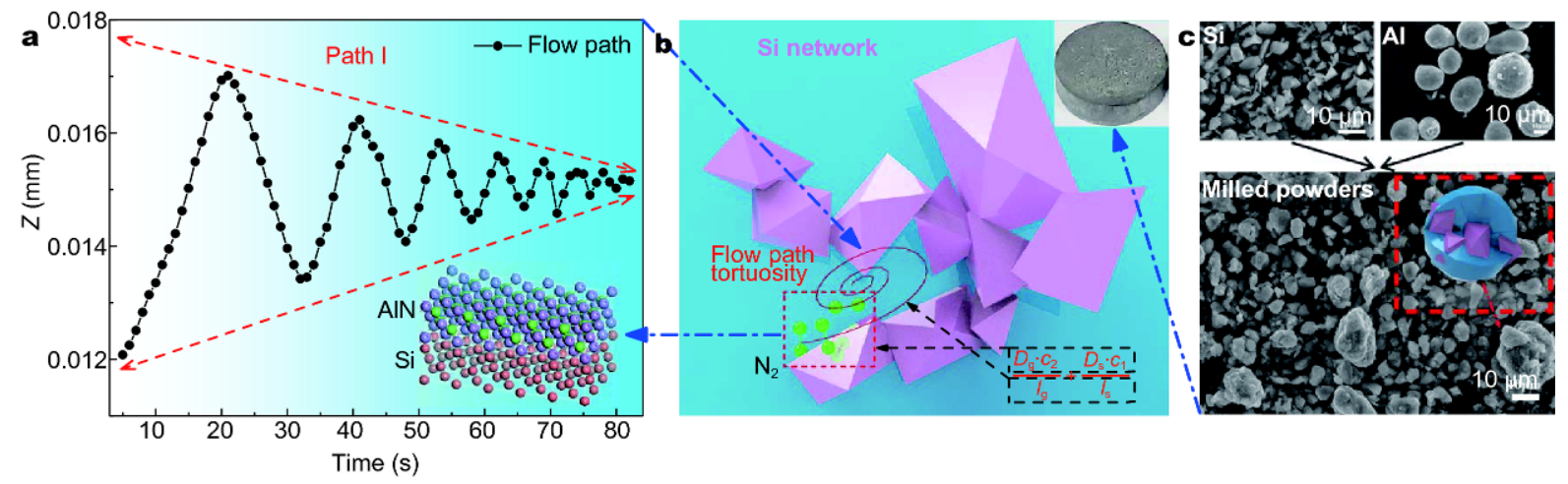

Figure 11 The flow path of Path I for Al-AlN-50Si ${ }^{\mathrm{B}}$ material (a) in Fig. 8(c). The mechanism of in situ synthesized AlN (b). SEM images of highenergy ball milled powders (c).

The curve shows a gradually weakened fluctuation inside the red dotted line. Due to the fact that the complex semicontinuous Si leads to strong turbulence in the flow path, not disordered anisotropic flow, it can be restricted by $\mathrm{Si}$ and cause relatively regular turbulence. The initial flow path is restricted by the semi-continuous $\mathrm{Si}$, and leads to the formation of original turbulence (the flow path tortuosity of Fig. 11b). With the advancing solidification, the amplitude of flow path is reduced gradually by solidification of semi-continuous $\mathrm{Si}$, and a part of $\mathrm{N}_{2}$ is enriched around the small $\mathrm{Si}$ connector and flow-reacted with $\mathrm{Al}$ (inside the red dotted box of Fig. 11b). The AlN is interconnected in the interpenetrating Si network, and the AlN-Si composite has good connectivity of $\mathrm{Si}$ and AlN phases shown as blue arrow in Fig. 11a. Therefore, the flow path is significantly affected by the semi-continuous $\mathrm{Si}$ structure and the advancing solidification, so that the in situ synthesis of AlN is strongly influenced by micro- structures and flow paths (black dotted box of Fig. 11b). In addition, during the high-energy ball milling process, some tiny Si particles are embedded into ductile $\mathrm{Al}$ particles and form some special compound powders with many defects and high surface energy, and these powders have an irregular cracked spherical structure (Fig. 11c).

Similarly, the in situ formation mechanism of AlN in $\mathrm{Al}-\mathrm{AlN}-50 \mathrm{Si}^{\mathrm{M}}$ material is presented in Fig. 12a-c. Fig. 12a shows the position of $z$ axis with the time increases from Path II (red box) of Fig. 9c, exhibiting a nearly linear relationship between the position and the sintering time. Compared with the semi-continuous $\mathrm{Si}$ of $\mathrm{Al}-\mathrm{AlN}-50 \mathrm{Si}^{\mathrm{B}}$ material, the isolated $\mathrm{Si}$ of $\mathrm{Al}-\mathrm{AlN}-50 \mathrm{Si}^{\mathrm{M}}$ material can entail relatively mild turbulence in the flow path. The flowing $\mathrm{N}_{2}$ and AlN can easily pass through $\mathrm{Si}$, and the in situ synthesis of AlN cannot be restricted by the isolated $\mathrm{Si}$ (Fig. 12b). Thus, the flow paths are mainly affected by the advancing solidification, $\mathrm{N}_{2}$ is hardly enriched around 


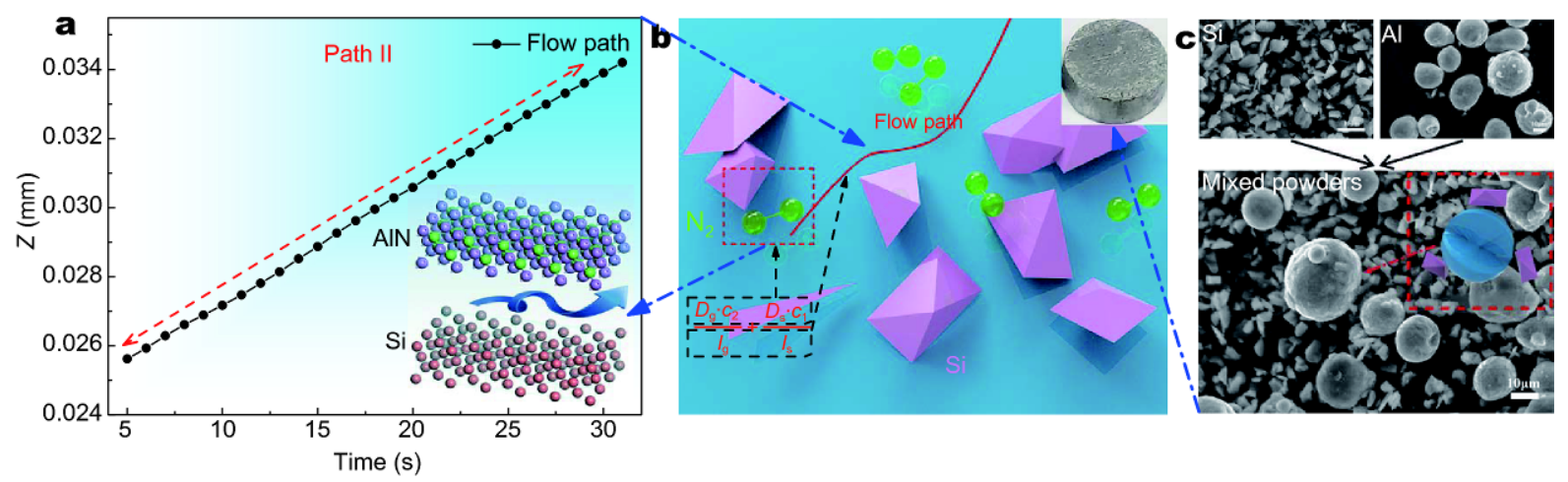

Figure 12 The flow path of Path II for Al-AlN-50Si ${ }^{\mathrm{M}}$ material (a) in Fig. 9(c). The mechanism of in situ synthesized AlN (b). SEM images of mixed powders (c).
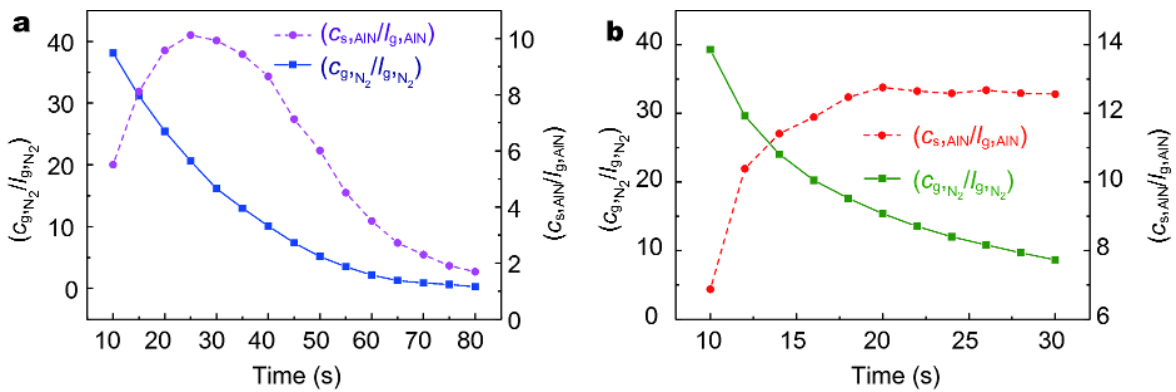

Figure 13 The $c_{\mathrm{g}, \mathrm{N}_{2}} / l_{\mathrm{g}, \mathrm{N}_{2}}$ and the $c_{\mathrm{s}, \mathrm{AlN}} / l_{\mathrm{s}, \mathrm{AlN}}$ curves of Al-AlN-50Si ${ }^{\mathrm{B}}$ material (a) and Al-AlN-50Si ${ }^{\mathrm{M}}$ material (b).

the $\mathrm{Si}$ and flow-reacted with $\mathrm{Al}$ (inside the red dotted box of Fig. 12b). Owing to the mixed powders with a relatively stable interface with poor wettability (Fig. 12c), the AlN and $\mathrm{Si}$ cannot form the continuous AlN-Si composite. In short, the in situ synthesis of AlN is strongly influenced by microstructures and flow paths (black dotted box of Fig. 12b). Therefore, the AlN is separated and agglomerated in the form of isolated structures shown as blue arrow in Fig. 12b.

\section{Flow-path and structure interaction}

RHS of Equation 7 can be written as the $\left(c_{\mathrm{g}, \mathrm{N}_{2}} / l_{\mathrm{g,N}}\right)+\left(c_{\mathrm{s}, \mathrm{AlN}} /\right.$ $\left.l_{\mathrm{s}, \mathrm{AlN}}\right)$. The dynamic evolution of the Path I and the Path II of Figs 8, 9 are further analyzed in Fig. 13 by tracking $c_{\mathrm{g}, \mathrm{N}_{2}} / l_{\mathrm{g}, \mathrm{N}_{2}}, c_{\mathrm{s}, \mathrm{AIN}} / l_{\mathrm{s}, \mathrm{AlN}}$ and $\left(c_{\mathrm{g}, \mathrm{N}_{2}} / l_{\mathrm{g,N}}\right)+\left(c_{\mathrm{s}, \mathrm{AlN}} / l_{\mathrm{s}, \mathrm{AlN}}\right)$ along the flow path in the simulation domain. Fig. 13a shows the $c_{\mathrm{g}, \mathrm{N}_{2}} / l_{\mathrm{g}, \mathrm{N}_{2}}$ and $c_{\mathrm{s}, \mathrm{AIN}} / l_{\mathrm{s}, \mathrm{AlN}}$ curves of the path (Path I, as marked in Fig. 8c) cross one channel, from 10 to $80 \mathrm{~s}$ (sintering time). In the Al-AlN-50Si ${ }^{\mathrm{B}}$ material, the $c_{\mathrm{g}, \mathrm{N}_{2}} /$ $l_{\mathrm{g}, \mathrm{N}_{2}}$ curve shows a rapid decrease and then tends to be stable finally, due to the continuous $\mathrm{N}_{2}$ consumption by flow-reaction. However, the $c_{\text {s.AIN }} / l_{\text {s.AIN }}$ curve first increased and then decreased. When the sintering time at
$25 \mathrm{~s}$, the $c_{\mathrm{s}, \mathrm{AlN}} / l_{\mathrm{s}, \mathrm{AIN}}$ reached the maximum due to the AlN enrichment in the flow path. The semi-continuous $\mathrm{Si}$ structure restricts and decreases the flow path of AlN. For the Al-AlN-50Si ${ }^{\mathrm{M}}$ material, the $c_{\mathrm{g}, \mathrm{N}_{2}} / l_{\mathrm{g}, \mathrm{N}_{2}}$ curve shows quite similar behavior to that of Al-AlN-50Si ${ }^{\mathrm{B}}$ material, but the large different in the $c_{\mathrm{s}, \mathrm{AIN}} / l_{\mathrm{s}, \mathrm{AlN}}$ curve. Because the Si islands cannot be able to effectively restrain the flow path of AlN, the relatively free flow path of AlN can cause the $c_{\mathrm{s}, \mathrm{AIN}} / l_{\mathrm{s}, \mathrm{AlN}}$ curve increasing slowly. Further, the $\left(c_{\mathrm{g}, \mathrm{N}_{2}} / l_{\mathrm{g}, \mathrm{N}_{2}}\right)$ $+\left(c_{s, \mathrm{AlN}} / l_{\mathrm{s}, \mathrm{AlN}}\right)$ curves of Al-AlN-50Si ${ }^{\mathrm{B}}$ and $\mathrm{Al}-\mathrm{AlN}-50 \mathrm{Si}^{\mathrm{M}}$ materials are shown in Fig. 14. Obviously, although they have small difference in the trend of curves, the decreased ratio of the $\left(c_{\mathrm{g}, \mathrm{N}_{2}} / l_{\mathrm{g}, \mathrm{N}}\right)+\left(c_{\mathrm{s}, \mathrm{AlN}} / l_{\mathrm{s}, \mathrm{AIN}}\right)$ curve of Al-AlN-50Si $\mathrm{B}^{\mathrm{B}}$ material is greater than that of $\mathrm{Al}-\mathrm{AlN}-50 \mathrm{Si}^{\mathrm{M}}$ material indicating that the in situ synthesis of AlN is affected by the $\left(c_{\mathrm{g}, \mathrm{N}_{2}} / l_{\mathrm{g}, \mathrm{N}_{2}}\right)+\left(c_{\mathrm{s}, \mathrm{AlN}} / l_{\mathrm{s}, \mathrm{AlN}}\right)$. Consequently, the in situ synthesis of AlN in Al-AlN-Si materials is strongly influenced by structure and flow-path. The dynamic microstructural evolution of Al-AlN-Si materials is dependent on the initial formation of microstructures prepared by different precursor powders. In this context, the Al-AlN-50Si materials were selected as the model materials, and the 3D scale models of Al-AlN-50Si ${ }^{\mathrm{B}}$ and 


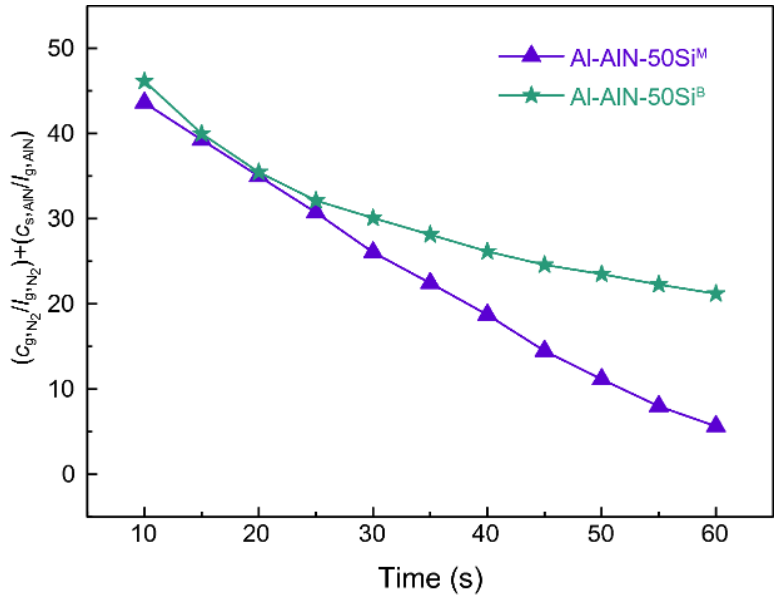

Figure 14 The $\left(c_{\mathrm{g}, \mathrm{N}_{2}} / l_{\mathrm{g}, \mathrm{N}_{2}}\right)+\left(c_{\mathrm{s}, \mathrm{AlN}} / l_{\mathrm{s}, \mathrm{AlN}}\right)$ curves of Al-AlN-50Si ${ }^{\mathrm{B}}$ and AlAlN-50Si ${ }^{\mathrm{M}}$ materials.

$\mathrm{Al}-\mathrm{AlN}-50 \mathrm{Si}^{\mathrm{M}}$ materials were constructed in parallel. In the present simulation, the flow paths of $\mathrm{Al}-\mathrm{AlN}-50 \mathrm{Si}^{\mathrm{B}}$ material were restricted by the semi-continuous $\mathrm{Si}$ structure, which lead to large flow deflection angles in the flow paths. These regions can create the strong turbulence with gradually weak fluctuation, thus the in situ synthesis of AlN was interconnected and surrounded by an interpenetrating Si network. However, the Al-AlN-50Si ${ }^{\mathrm{M}}$ material flow can easily pass through the isolated $\mathrm{Si}$ structure, due to its small flow deflection angles. The mild turbulence with linear relationship can affect the in situ synthesis of AlN in the flow paths. The AlN was separated by the isolated $\mathrm{Si}$ and agglomerated in the matrix.

\section{CONCLUSION}

In this work, we have designed and prepared the Al-AlN$\mathrm{Si}$ materials with semi-continuous and isolated structures, and then the 3D scale models of $\mathrm{Al}-\mathrm{AlN}-50 \mathrm{Si}^{\mathrm{B}}$ and $\mathrm{Al}-$ $\mathrm{AlN}-50 \mathrm{Si}^{\mathrm{M}}$ materials were constructed based on the phase identification and microstructure analysis. From our experimental and simulative study we conclude:

(1) The Al-AlN-50Si ${ }^{\mathrm{B}}$ material (prepared by high-energy ball milled powders) exhibits the characteristic semicontinuous AlN-Si structures, while the $\mathrm{Al}-\mathrm{AlN}-50 \mathrm{Si}^{\mathrm{M}}$ material (prepared by mixed powders) shows the isolated $\mathrm{Si}$ and AlN islands.

(2) The semi-continuous Si can lead to the large flow deflection angles, attributed to the more anisotropic flow channels in the matrix. The formation of AlN is not only affected by the advancing solidification interface but also limited by the Si structure.

(3) The semi-continuous with more anisotropic struc- ture can create the strong turbulence with gradually weakened fluctuation in the flow-path. However, the isolated Si structure shows the mild turbulence with linear relationship in the flow-path that can significantly influence the formation of interconnected AlN and isolated AlN in the matrix.

(4) The decreased ratio of the $\left(c_{\mathrm{g}, \mathrm{N}_{2}} / l_{\mathrm{g}, \mathrm{N}_{2}}\right)+\left(c_{\mathrm{s}, \mathrm{AIN}} / l_{\mathrm{s}, \mathrm{AIN}}\right)$ curve of $\mathrm{Al}-\mathrm{AlN}-50 \mathrm{Si}^{\mathrm{B}}$ material is greater than that of $\mathrm{Al}-$ $\mathrm{AlN}-50 \mathrm{Si}^{\mathrm{M}}$ material, resulting in the formation of interpenetrating $\mathrm{AlN}$ in the $\mathrm{Al}-\mathrm{AlN}-50 \mathrm{Si}^{\mathrm{B}}$ material. In summary, the in situ synthesis of AlN is strongly affected by the interaction of structure and flow-path.

\section{Received 30 October 2017; accepted 27 December 2017;} published online 31 January 2018

1 Kang N, Coddet P, Chen C, et al. Microstructure and wear behavior of in-situ hypereutectic Al-high Si alloys produced by selective laser melting. Mater Des, 2016, 99: 120-126

2 Swaminathan S, Srinivasa Rao B, Jayaram V. The production of AlN-rich matrix composites by the reactive infiltration of $\mathrm{Al}$ alloys in nitrogen. Acta Mater, 2002, 50: 3095-3106

3 Qiu J, Zhao M, Zhao Q, et al. Aluminum-based materials for advanced battery systems. Sci China Mater, 2017, 60: 577-607

4 Wang Y, Guan R, Hou D, et al. The effects of eutectic silicon on grain refinement in an $\mathrm{Al}-\mathrm{Si}$ alloy processed by accumulative continuous extrusion forming. J Mater Sci, 2017, 52: 1137-1148

5 Chen C, Cui C, Zhao L, et al. The formation mechanism and interface structure characterization of in situ AlN/Al composites. J Composite Mater, 2016, 50: 495-506

6 Ye HZ, Liu XY, Luan B. In situ synthesis of AlN particles in Mg-Al alloy by $\mathrm{Mg}_{3} \mathrm{~N}_{2}$ addition. Mater Lett, 2004, 58: 2361-2364

7 Kondoh K, Kimura A, Watanabe R. Cavitation toughness of in situ nitrided Al-AlN composite sintered material. Powder Metallurgy, 2001, 44: 157-160

8 Wang Z, Tong Y, Wang Y. Promoting effect of silicon particles on gas-diffusion-reaction system: In-situ synthesis of AlN in Al-Si materials. J Alloys Compd, 2018, 735: 13-22

9 Lee KB, Sim HS, Kwon H. Fabrication of Al/AlN composites by in situ reaction. J Mater Sci, 2006, 41: 6347-6352

10 Ye HZ, Liu XY, Luan B. In situ synthesis of AlN in Mg-Al alloys by liquid nitridation. J Mater Processing Tech, 2005, 166: 79-85

11 Zheng Q, Reddy RG. Mechanism of in situ formation of AlN in Al melt using nitrogen gas. J Mater Sci, 2004, 39: 141-149

12 Kobatake H, Brillo J, Schmitz J, et al. Surface tension of binary AlSi liquid alloys. J Mater Sci, 2015, 50: 3351-3360

13 Fatahalla N, Hafiz M, Abdulkhalek M. Effect of microstructure on the mechanical properties and fracture of commercial hypoeutectic Al-Si alloy modified with $\mathrm{Na}, \mathrm{Sb}$ and Sr. J Mater Sci, 1999, 34: 3555-3564

14 Heiberg G, Nogita K, Dahle AK, et al. Columnar to equiaxed transition of eutectic in hypoeutectic aluminium-silicon alloys. Acta Mater, 2002, 50: 2537-2546

15 Shahani AJ, Gulsoy EB, Roussochatzakis VJ, et al. The dynamics of coarsening in highly anisotropic systems: Si particles in Al-Si liquids. Acta Mater, 2015, 97: 325-337

16 Zhang Q, Liu X, Dai H. Re-formation of AlP compound in Al-Si melt. J Alloys Compd, 2009, 480: 376-381 
17 Zuo M, Zhao D, Teng X, et al. Effect of $\mathrm{P}$ and Sr complex modification on Si phase in hypereutectic Al-30Si alloys. Mater Des, 2013, 47: 857-864

18 Kalemtas A, Topates G, Bahadir O, et al. Thermal properties of pressureless melt infiltrated AlN-Si-Al composites. Trans Nonferrous Met Soc China, 2013, 23: 1304-1313

19 Myhr OR, Grong $\varnothing$, Fjær HG, et al. Modelling of the microstructure and strength evolution in $\mathrm{Al}-\mathrm{Mg}-\mathrm{Si}$ alloys during multistage thermal processing. Acta Mater, 2004, 52: 4997-5008

20 Arik $H$. Effect of mechanical alloying process on mechanical properties of $\alpha-\mathrm{Si}_{3} \mathrm{~N}_{4}$ reinforced aluminum-based composite materials. Mater Des, 2008, 29: 1856-1861

$21 \mathrm{Wu}$ Y, Zong Y, Jin J. Grain growth in a nanostructured AZ31 Mg alloy containing second phase particles studied by phase field simulations. Sci China Mater, 2016, 59: 355-362

22 Wu M, Ludwig A. Modeling equiaxed solidification with melt convection and grain sedimentation-I: Model description. Acta Mater, 2009, 57: 5621-5631

23 Eiken J, Apel M, Liang SM, et al. Impact of P and Sr on solidification sequence and morphology of hypoeutectic $\mathrm{Al}-\mathrm{Si}$ alloys: Combined thermodynamic computation and phase-field simulation. Acta Mater, 2015, 98: 152-163

24 Yuan P, Gu D, Dai D. Particulate migration behavior and its mechanism during selective laser melting of $\mathrm{TiC}$ reinforced $\mathrm{Al}$ matrix nanocomposites. Mater Des, 2015, 82: 46-55

25 Wang Z, Wang F Z, Wang X, et al. Three-dimensional modelling and numerical simulation on segregation during $\mathrm{Fe}-\mathrm{Pb}$ alloy solidification in a multiphase system. Acta Phys Sin, 2014, 63: 205-211

26 Wang Z, Wang F, He Y, et al. Numerical study on free-cutting phase precipitation behavior in Fe-Bi-Mn ternary alloy multiphase transformation-diffusion system. Acta Metall Sin, 2014, 50: 13931402

27 Wu M, Li J, Ludwig A, et al. Modeling diffusion-governed solidification of ternary alloys-Part 1: Coupling solidification kinetics with thermodynamics. Comput Mater Sci, 2013, 79: 830-840
28 Huang LJ, Geng L, Peng HX. Microstructurally inhomogeneous composites: Is a homogeneous reinforcement distribution optimal? Prog Mater Sci, 2015, 71: 93-168

29 Suehiro T, Tatami J, Meguro T, et al. Synthesis of spherical AlN particles by gas-reduction-nitridation method. J Eur Ceramic Soc, 2002, 22: 521-526

30 Kim WY, Kang JG, Park CH, et al. Thermodynamics of aluminum, nitrogen and AlN formation in liquid iron. ISIJ Int, 2007, 47: 945954

31 Beckermann C, Viskanta R. Mathematical modeling of transport phenomena during alloy solidification. Appl Mech Rev, 1993, 46: $1-27$

32 Madison J, Spowart J, Rowenhorst D, et al. Modeling fluid flow in three-dimensional single crystal dendritic structures. Acta Mater, 2010, 58: 2864-2875

33 Založnik M, Combeau $\mathrm{H}$. Thermosolutal flow in steel ingots and the formation of mesosegregates. Int J Thermal Sci, 2010, 49: 15001509

34 Duhr S, Braun D. Two-dimensional colloidal crystals formed by thermophoresis and convection. Appl Phys Lett, 2005, 86: 131921

Acknowledgements This work was supported by the financial support of the National Natural Science Foundation of China (51171146 and 51101177) and the Program for Key Science and Technology Innovative Research Team of Shaanxi Province (2013KCT-05).

Author contributions Wang $\mathrm{Z}$ and Wang $\mathrm{Y}$ designed experiments; Wang $\mathrm{Z}$ designed simulations; Wang Z, Wang $\mathrm{X}$ and Tong $\mathrm{Y}$ carried out experiments; Wang $Z$ carried out simulations; Wang $Z$ analyzed experimental and simulations results; Wang $\mathrm{Z}$ and Wang $\mathrm{Y}$ wrote the manuscript.

Conflict of interest The authors declare no conflict of interest.

Supplementary information Supplementary data are available in the online version of this article. 

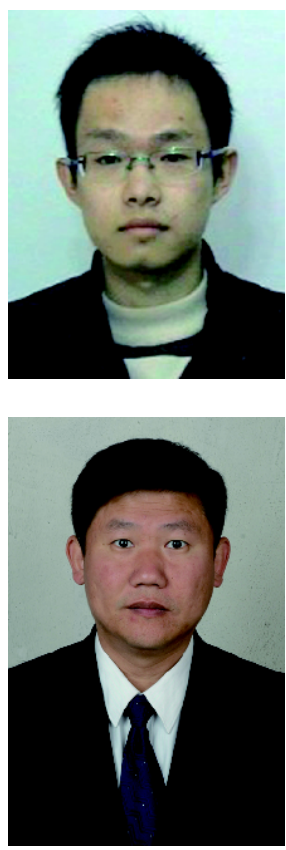

Zhe Wang is now a PhD candidate of the School of Sciences, Xi'an Jiaotong University. His research interests focus on the preparation and properties of Al-Si based composites and their applications in electronic packaging.

Yaping Wang received his PhD degree in material science from Xi'an Jiaotong University in 1998. Currently, he is a professor at Xi'an Jiaotong University. His research interests include non-pressure impregnation of $\mathrm{Si}$ - $\mathrm{Al}$ electrical packaging materials, preparation of $\mathrm{Cu}-\mathrm{Cr}$ and $\mathrm{Ag}-\mathrm{SnO}_{2}$ contact materials and industrial manufacture of $\mathrm{Cu}-\mathrm{Al}_{2} \mathrm{O}_{3}$ composite materials.

\section{微观结构和流动路径对AIN原位合成的影响: Al-AIN-Si微观组织形成的动力学演变研究}

王哲 ${ }^{1^{*}}$, 王欣 ${ }^{1}$, 全毅刚 ${ }^{1}$, 王亚平 ${ }^{1,2^{*}}$

摘要 本文采用粉末冶金结合原位反应方法制备了不同结构的Al-AlN-Si复合材料. 基于物相鉴别和显微分析方法, 建立了具有半连续Si 结构(由高能球磨粉末制备)和孤岛 Si结构(由混合粉末制备)的Al-AlN-50Si微观模型, 使用计算流体动力学(CFD)方法对 Al-AlN-50Si微观 组织形成过程进行了研究, 并分析了其动力学演变机理. 数学模型和模拟结果表明: 微观结构和流动路径 $\left(\left(c_{\mathrm{g}, \mathrm{N}_{2}} / l_{\mathrm{g}, \mathrm{N}_{2}}\right)+\left(c_{\mathrm{s}, \mathrm{AIN}} / l_{\mathrm{s}, \mathrm{AlN}}\right)\right)$ 会强烈影 响AlN的原位合成. 对于 $\mathrm{Al}-\mathrm{AlN}-50 \mathrm{Si}^{\mathrm{B}}$ (由高能球磨粉末制备)材料, 其流动路径会被半连续 $\mathrm{Si}$ 结构限制而促进强湍流的形成, 这种逐渐减弱

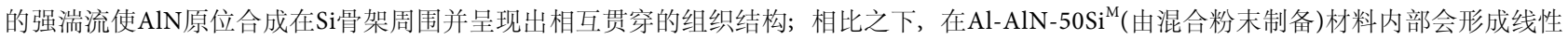
趋势的弱湍流, 其流动路径可以很容易的绕开孤岛 $\mathrm{Si}$, 使 $\mathrm{AlN}$ 相被隔离并富集形成在基体中. 该工作为原位反应系统中复合材料微观组织 动力学演变过程的研究提供了新的思路. 